\title{
Statistical Modelling of the Microclimate in a Naturally Ventilated Greenhouse
}

\section{J. Litaga $\frac{1}{2}$ F.J. Baptista ${ }^{\underline{2}}$, J.F. Meneses ${ }^{\frac{3}{2}}$, L.M. Navas ${ }^{4}$, B.J. Bailey ${ }^{\underline{5}}$ and V. Sánchez- Girón ${ }^{6},{ }^{2},{ }^{-}$}

${ }^{1}$ Dept. de Estadística y MGA, ETSI Agrónomos, Universidad Politécnica de Madrid, Ciudad Universitaria, 28040 Madrid, Spain

${ }^{2}$ Dept. Engenieria Rural, Universidade de Évora, Apartado 94, 7002-554 Évora Portugal

${ }^{3}$ Instituto Superior de Agronomia, Tapada da Ajuda, 1349-017 Lisboa Codex, Portugal

${ }^{4}$ Dept. de Ingeniería Agrícola y Forestal, ETSI Agrarias, Universidad de Valladolid, Av. Madrid 144, Palencia, Spain

${ }^{5}$ Process Engineering Division, Silsoe Research Institute, Wrest Park, Silsoe, Bedford MK45 4HS, UK.

${ }^{6}$ Dept. de Ingeniería Rural, ETSI Agrónomos, Universidad Politécnica de Madrid, Ciudad Universitaria, 28040 Madrid, Spain

The time-series models introduced in this paper were developed to estimate and forecast temperature and humidity dynamics in an unheated, naturally ventilated greenhouse in Lisbon, Portugal. External and internal climatic data recorded over four consecutive months during the tomato (Lycopersicon esculentum, Mill) growing season were used to build and validate forecasting models for simulating environmental conditions inside the greenhouse. The statistical models were assessed with co-integration and error correction methods, using hourly data. The main variables considered to estimate the internal air temperature were external temperature, ventilation rate and solar radiation. Internal relative humidity was predicted primarily from external relative humidity, ventilation rate and evapotranspiration. Internal greenhouse air temperature and relative humidity were closely related to solar radiation, external air temperature and ventilation rate. Despite the large number of parameters involved, both models provided a reliable prediction of the system dynamics. A comparison of measured and simulated data showed that the models were able to forecast internal greenhouse conditions reasonably well.

Available online at:

http://www.sciencedirect.com/science?_ob=ArticleURL\&_udi=B6WXV-4H98T53$1 \&$ _user $=10 \&$ _coverDate $=11 \% 2 \mathrm{~F} 30 \% 2 \mathrm{~F} 2005 \&$ _rdoc $=10 \&$ fmt $=$ high $\&$ _orig=browse \&_srch=doc-

info(\%23toc\%237168\%232005\%23999079996\%23607961\%23FLA\%23display\%23Vo lume)\&_cdi=7168\&_sort=d\&_docanchor $=\& \_c t=13 \& \_$acct $=$C000050221\&_version $=1$ \&_urlVersion=0\&_userid=10\&md5=20154d89751d8b7908e3094b9e9c7d64 